\title{
Editorial for EAIT issue 2, 2020
}

\section{Arthur Tatnall ${ }^{1}$}

Published online: 19 February 2020

(C) Springer Science+Business Media, LLC, part of Springer Nature 2020

Education and Information Technologies (EAIT) is the official journal of the Technical Committee on Education (TC3) of the International Federation for Information Processing (IFIP). It covers the complex relationships between information and communication technologies and education, from the micro of specific applications or instances of use in classrooms to macro concerns of national policies and major projects; from classes of five year olds to adults in tertiary institutions; from teachers and administrators, to researchers and designers; from institutions to open, distance and lifelong learning. The journal's breadth of coverage allows EAIT to examine fundamental issues at all levels, discuss specific instances and cases, draw inference and probe theory. This journal is embedded in the research and practice of professionals.

In addition to the 'regular' articles, this issue of EAIT has two special sections:

\section{Learning management systems and big data Technologies for Higher Education}

Edited by: Shah J Miah (Victoria University, Melbourne, Australia).

Muhammed Miah (Tennessee State University, Nashville, USA).

Jun Shen (University of Wollongong, NSW, Australia).

\section{The trends of blended learning in South East Asia}

Edited by: Ford Lumban Gaol (Bina Nusantara University, Jakarta, Indonesia). Fonny Hutagalung (University of Malaya, Kuala Lumpur, Malaysia).

The first of the 'regular' articles in this issue comes from Khadijeh Aghaei and Mojtaba Rajabi (Gonbad Kavous University, Iran), Koo Yew Lie (University of London, UK) and Fereshte Ajam (Islamic Azad University Gorgan Branch, Iran) and is titled: Flipped learning as situated practice: A contrastive narrative inquiry in an EFL classroom. In Iran, traditional lecture-oriented teaching is still the norm in courses on English as a foreign language, but an innovative teaching model is becoming popular across non-English-speaking subjects. The new model flips the usual classroom paradigm, and students learn primary concepts outside the classroom and class time is reserved for more active problem-based learning. This study on the new model's impact

Arthur Tatnall

Arthur.Tatnall@vu.edu.au

1 Victoria University, Melbourne, Australia 
employed narrative inquiry using data from interviews and observational field notes. The article discusses the results.

The effects of the flipped classroom model designed according to the ARCS motivation strategies on the students' motivation and academic achievement levels from Songül Karabatak and Hakan Polat (Firat University, Turkey) follows. The reported study aimed to determine the effects of the traditional classroom approach, distance education model and the flipped classroom and was designed according to ARCS (attention, relevance, confidence and satisfaction) motivation strategies on motivation and academic achievement levels. Their results indicated that academic achievement levels of students in the flipped classroom using ARCS motivation strategies were significantly higher than those of students in the distance education classroom model and traditional classrooms.

Alireza Badeleh (Farhangian University, Iran) points out that advances in technology have made it necessary to make use of new educational methods in educational systems in their article: The effects of robotics training on students' creativity and learning in physics. The research design was pre-test/post-test quasi-experimental, including a control and a treatment group of 11th grade students in Tehran. After an eightsession treatment period, data was collected through employing the Torrance Creativity Questionnaire including four dimensions namely fluidity, flexibility, innovation, and detailed explanation in items, learning points, and a package of training on robotic constructs in physics. Findings indicated that Robotics training influenced and improved creativity and learning in physics among the participants.

Cândida Barros, Ana Amélia Carvalho and António Salgueiro (University of Coimbra, Portugal) then offer an article titled: The effect of the serious game Tempoly on learning arithmetic polynomial operations. They note that research on learning through serious games has gained importance in recent years. Their research involved developing the serious game Tempoly which was concerned with learning of the four arithmetic operations on polynomials. They conclude that the students liked playing the game and considered that it helped them learning the polynomial operations, and that what they learned in class was useful to play the game. The study revealed that the students that had more time to play the game did play more out of the class.

Successful transition to synchronous learning environments in distance education: A research on entry-level synchronous facilitator competencies comes from Amber Phelps (Bow Valley College, Canada) and Dimitrios Vlachopoulos (Amsterdam University of Applied Sciences, Netherlands). They investigated synchronous education and its integration at various levels and capacities in distance education, as this offers learners and facilitators a virtual web-conferencing environment where, although they may be geographically separated, they are afforded the flexibility of being virtually present in a shared real-time space. Their research aimed to reflect on what skills synchronous facilitators perceive as necessary for entry-level facilitators to adequately support learners in the synchronous learning environment.

Online learning is common in higher education but has its drawbacks, and Ahmet Berk Ustun (Bartin University, Turkey) and Monica Walch Tracey (Wayne State University, USA) write on how this may be improved in: An effective way of designing blended learning: A three phase design-based research approach. They argue that blended learning (BL) has emerged as an alternative to alleviate the challenges of online learning. Their design-based research study aimed to determine what elements were needed to assist a higher education instructor inexperienced in designing and 
teaching a BL course to successfully create and implement it, and to document the instructor's perceptions about the first experience of teaching a BL course. Their article discusses this.

Next is an article by Fatima Ezzahraa Louhab (University Hassan II of Casablanca, Morocco), Ayoub Bahnasse (University Hassan II of Casablanca, Morocco), Faycal Bensalah2 \& Azeddine Khiat (University Hassan II of Casablanca, Morocco), Yousaf Khiat (Mohamed V Souissi University, Morocco) and Mohamed Talea (University Hassan II of Casablanca, Morocco). Their article: Novel approach for adaptive flipped classroom based on learning management system discusses how learning activity takes on different methods, and approaches virtual learning using learning management systems and the flipped classroom concept. In this paper they present a model that can be combined with the Moodle platform to provide students with an adapted content according to their knowledge level and skills, and instructors the ability to manage the learning mechanism of their students in the context of flipped learning.

Environment based virtual interaction to enhance motivation of STEM education: The qualitative interview design and analysis from: Sazrol Fadzli (Universiti Kebangsaan Malaysia), Jamaiah Yahaya (Universiti Kebangsaan Malaysia), Aziz Deraman (Universiti Malaysia Terengganu, Malaysia), Abdul Razak Hamdan (Universiti Kebangsaan Malaysia), Lilia Halim (Universiti Kebangsaan Malaysia), Noor Zaitun Yahaya (Universiti Kebangsaan Malaysia), Mohamed Shahrir Mohamed Zahari (Universiti Kebangsaan Malaysia) and Izhar Abadi Ibrahim Rais (Department of Mineral and Geoscience, Mineral Research Centre, Malaysia) notes that the development of ICT has led to the use of simulation and visualisation $(\mathrm{S} \& \mathrm{~V})$ in various domains as a useful virtual interactive tool. Their literature study identified five main components that may influence the STEM motivation among school children through the integration of S\&V. They are: Simulation and Visualisation for CAI, Motivation Level and Process, Green Environmental Data, Learning Outcome and Adaption to Scenario.

A behavioral intention model for SaaS-based collaboration services in higher education points out that despite numerous potential benefits of cloud computing usage, there are still some users reluctant to adopt this technology. Elaheh Yadegaridehkordi (University of Malaya, Malaysia), Mehrbakhsh Nilashi (Universiti Teknologi Malaysia), Liyana Shuib (University of Malaya, Malaysia) and Sarminah Samad (Princess Nourah Bint Abdulrahman University, Saudi Arabia) aimed to investigate the factors that influence student adoption of cloud computing in higher education settings and to generate a set of decision rules to guide through a series of critical decisions needed in this adoption process. Their results showed that task-technology fit, performance expectancy, effort expectancy, social influence, self-efficacy, collaboration technology experience, peer and superior influence and familiarity with group members are significant predictors of intention to adopt cloud computing.

Ragad M. Tawafak (University Malaysia Pahang and AlBuraimi University College, Oman), Awanis B. T. Romli (University Malaysia Pahang), Ruzaini bin Abdullah Arshah (University Malaysia Pahang), and Sohail Iqbal Malik (AlBuraimi University College, Oman) next write on: Framework design of university communication model (UCOM) to enhance continuous intentions in teaching and e-learning process. They argue that a problem with continuous intention in e-learning applications relies on the type of technology used that changes from one university to another. Their study aimed to design a framework developed from University Communication Model (UCOM) to 
enhance the teaching and learning process of universities which they claim gives a high rate of significance and accurate results by examining the relationship between the factors of e-learning application and the technology acceptance model (TAM).

$A$ vision of the digital future - government funding as a catalyst for 1 to 1 computing in schools by Therese Keane and William Keane (Swinburne University of Technology, Australia) reports on how the Digital Education Revolution (DER) funding enabled one school to transition from having shared computers amongst students to a personalised one computer to one student ratio. They aimed to explore how the unexpected funding impacted on the school and a catalyst for change that affected many stakeholders including students, teachers and parents. The paper explored the school's computer situation prior, during and post funding to illustrate how funding made significant changes in practice both in many classrooms in the teaching and learning program, and professional staff learning.

Quality of service acceptance in cloud service utilization: An empirical study in Palestinian higher education institutions by Marwan Bsharat and Othman Ibrahim (University of Technology Malaysia) notes that cloud service is an emerging technology in Higher education institutions, but that quality of service (QoS) is not given sufficiently attention. In their research, previous QoS models and frameworks of research done in this field were reviewed. Their results indicated a positive significant relationship of technological and environmental variables with QoS acceptance. They also developed a model to assist decision makers to develop strategic utilisation plans of cloud service by exploring evaluation of QoS acceptance variables of current cloud service.

The next paper analyses student views on an e-learning intervention that incorporated a content development tool and computer algebra systems, aimed at improving performance and applicability of mathematics knowledge. Perspectives for effective integration of e-learning tools in university mathematics instruction for developing countries from Edwin Akugizibwe (Mountains of the Moon University, Uganda) and Jeong Yong Ahn (Chonbuk National University, South Korea) relied on open source tools with high usability both online and offline, that can be customised to address the peculiarities of mathematics instruction in developing countries. Their key findings showed that usability and detailed feedback were the qualities of computer algebra system that were most desired by students.

Many factors might influence the current place and the role of information and communication technologies in social matters, including education, say Salih Bardakci and Tuğba Kocadağ Ünver (Tokat Gaziosmanpasa University, Turkey). The next article, Preservice ICT teachers' technology metaphors in the margin of technological determinism, indicates that one such factor might be conception of technology. Their study aimed to examine preservice ICT teachers' technology metaphors by linking to concepts of technological determinism. They found that technology is widely regarded in relation to a utopian and improved state of affairs and argue that revealing preservice ICT teachers technology metaphors might enable scholars to broaden more realistic perspectives regarding how technology might be integrated into education.

Is Moodle or WhatsApp the preferred e-learning platform at a South African university? First-year students' experiences, describes research by Cedric Bheki Mpungose (University of KwaZulu-Natal, South Africa). In South African universities, first-year students are compelled to use the Moodle elearning management platform, but this creates challenges as some students struggle to use Moodle owing to their 
disadvantaged school background. These students, however, are familiar with and good at using the WhatsApp social media platform. Findings showed that while students only had the option of using a formal e-learning platform (Moodle), they would prefer to use their more familiar informal e-learning platform (WhatsApp) and that this could be used to improve e-learning.

Recognizing competencies vs. completion vs. participation: Ideal roles for webenabled digital badges, is by Daniel T. Hickey and Grant T. Chartrand (Indiana University Learning Sciences Program, USA). The authors note that open digital badges are new credentials that can contain specific claims and links to web-enabled evidence, can circulate in networks and are helping facilitate broader shifts away from measuring, accrediting, and credentialing achievement and towards capturing, validating, and recognising learning. Their study of funded efforts to develop badges found that none of the efforts to develop competency badges (for demonstrating specific competencies) resulted in thriving badge-based ecosystems, while four of the five efforts to develop participation badges (for engaged participation in social learning) did so.

Nina Bergdahl, Jalal Nouri and Uno Fors (Stockholm University, Sweden) next write on: Disengagement, engagement and digital skills in technology-enhanced learning. They point out that with even though there is a strong consensus that engagement is necessary for students to succeed in school, the increasing digitalisation of education the relationship between student engagement in Technology-enhanced Learning (TEL) and digital skills has remained largely unexplored. They hypothesised that students reporting high and low levels of general engagement display differences in terms of their engagement in TEL, and students' digital skills correlate with their engagement in and disengagement in TEL, which in turn is related to their learning outcomes. They found significant correlations between students' digital skills and engagement in TEL, showing that the possession of high levels of digital skill is related to its engagement.

The use of online intervention in providing career counselling and guidance is one of the practical methods to help people improve their understanding of existing career conditions say Nooshin Pordelan, Ahmad Sadeghi, Mohammad Reza Abedi and Marjan Kaedi (University of Isfahan, Iran) in their article: Promoting student career decision-making self-efficacy: An online intervention. Their study involved investigation of the effect of online counselling and face-to-face counselling with a guidance paradigm on the career decision-making self-efficacy of students of the University of Isfahan. They found that students in an online group were similar to students in a faceto-face group in terms of career decision-making self-efficacy and both interventions promoted career decision-making self-efficacy of students.

Electronic portfolio development and narrative reflections in higher education: Part and parcel of the culture? In this article, Khadeegha Alzouebi (Hamdan Bin Mohammed Smart University, United Arab Emirates) describes a study to investigate the effective use of electronic portfolios in the educational context of graduate students in a major research university in the UAE. It is noted that use of electronic portfolios with university students has many benefits including advancing learning, assessment and evaluation and that this is an innovative instructional approach that has not widely been used in the UAE. The article describes a study of e-portfolio development, rubric and reflective narratives and how to develop this in university teaching and learning, along with areas of attainment. A key recommendation is that instructors and 
institutions can effectively utilise e-portfolios to improve learning and assessment, course delivery, and program outcomes.

Ali Kürşat Erümit (Trabzon University, Turkey) then looks at: Effects of different teaching approaches on programming skills. In the study, three different types of activities prepared with Scratch on sixth grade students' attitudes towards computer technologies, algorithmic thinking skills and reflective thinking skills on problem solving were investigated. It was found that although the same programming tool and similar code blocks were used in three applications, selected activities resulted in different effects on students. The study revealed the importance of 'activity type', which is often neglected as a variable in studies investigating the different effects of block-based visual programming tools.

Pupils' ways of understanding programmed technological solutions when analysing structure and function by Anne-Marie Cederqvist (University of Gothenburg, Sweden) follows. The author notes that programming has recently become part of Swedish technology education and that pupils should be able to analyse existing programmed technological solutions and be able to design new ones. The aim of the reported study was to investigate pupils' different ways of understanding programmed technological solutions when analysing their structure and function. The research project used interviews in which prepared contexts were used: Micro:bit constructions and programmed technological solutions from everyday life. The results show that pupils have different approaches to programmed technological solutions based on what parts are discerned in the prepared contexts, and also that pupils approach the two prepared contexts differently.

Correlations of self-perception in reading and in writing, reading and writing performance in web-mediated and conventional writing instruction by Maria B. Cequeña (Senior High School, Catholic Filipino Academy/Barcelona Academy, Philippines) notes that the advent of ICT has revolutionised ESL writing instruction. A quasi-experiment with two groups of freshman college students investigated the correlations of self-perception in reading and in writing, reading performance and writing performance. One group was exposed to Web-Mediated Instruction and the other group taught using the Conventional Method. The author argues that reading performance is insignificantly correlated with self-perception in reading and self-perception in writing and that it was found that in each, self-perception in reading was positively correlated with self-perception in writing.

An empirical investigation into the perceived effectiveness of collaborative software for students' projects by Felix Nti Koranteng, Francis K Sarsah and Eric Kuada (GIMPA, Ghana) and Samuel Adu Gyamfi (University of Education, Ghana) follows. In the education sector, collaborative software such as GoogleDocs is pervasively used by both faculty and students as is enables frequent, cheaper and faster communication opportunities. However, little evidence exists on the factors that influence its use and effectiveness particularly for students' projects in developing countries. This article describes research extending the IS Success model to examine the factors that affect the perceived effectiveness of collaborative software for students' projects. PLS-SEM was adopted to estimate the proposed relationships. Information Quality, Service Quality and Primary Task Support had significant influence on Intention to Use whereas SelfEfficacy and System Quality did not. Results showed stakeholders prioritise user satisfaction to improve the effectiveness of collaborative software for students' projects. 
Natasha Nyanja and Evaristo Musonda (University of Zambia) then offers a paper that highlights the effects brought about by the implementation of the ICT subject in the Zambian primary education curriculum. It is titled: A review of the ICT subject implementation in schools: a perspective of Lusaka Province (Zambia). The paper describes how various schools have implemented the new subject, its effects on schools, challenges faced with implementing the subject and remedies to counter the challenges. Suggestions are made on how to address challenges and improve the subject adoption rate. It is stressed that without proper resources, infrastructure and administrative support, the effective implementation of the ICT in education subject cannot be achieved.

Using computer-assisted pronunciation teaching (CAPT) in English pronunciation instruction: A study on the impact and the Teacher's role by Abbas Pourhosein Gilakjani and Ramin Rahimy (Islamic Azad University, Iran) begins by noting that Computer-Assisted Pronunciation Teaching (CAPT) provides EFL teachers with more alternatives to help learners who have serious problems in learning pronunciation. It also provides EFL learners with a private, stress-free environment where they can have access to an enormous amount of input and repetitive practice pronunciation at their own pace. The reported study investigated Iranian teachers' role in using CAPT in teaching pronunciation. Findings indicated significant pronunciation improvement in the experimental group of the learners who received CAPT instruction from their teachers.

Massive Open Online Courses (MOOC) made the promise of offering unrestrictive and unselective educational opportunities to learners worldwide say Nikoletta Agonács and João Filipe Matos (Universidade de Lisboa, Portugal), Daniela Bartalesi-Graf and David N. O'Steen (Wellesley College, USA) in their article: Are you ready? Selfdetermined learning readiness of language MOOC learners. They note that the specific learning environment of the MOOC requires high autonomy and flexibility in learning and their research objective was to select and characterise highly selfdetermined learners and to examine the relationship between self-determined learning characteristics of this specific learner cohort. A discussion of the implications and suggestion for MOOC design follows.

Ana C. Calderon, Deiniol Skillicorn, Andrew Watt and Nick Perham (Cardiff Metropolitan University, UK) then write on: A double dissociative study into the effectiveness of computational thinking. In their article they propose the first steps towards a rigorous analysis of the effectiveness of an emerging pedagogy, Computational Thinking. They found that two aspects of the pedagogy have a positive effect with regard to enhancing two cognitive processes, namely in sequential thinking and in abstract thinking. The specific components they investigated were algorithmic thinking and abstraction, and they found a positive correlation between enhancements of sequentiality and abstract thinking.

Using Makey-Makey for teaching electricity to primary school students, a pilot study begins by remarking that primary school students find it difficult to grasp concepts related to electricity, but that tangible user interfaces, such as Makey-Makey, offer an interesting alternative for teaching this subject. Emmanuel Fokides and Alexandra Papoutsi (University of the Aegean, Greece) report that they divided their students into three groups to investigate this. Everyday materials for making circuit boards were used for the teaching of the first group, simulations were used in the second, and in the third MakeyMakeys were utilised. Bybee's 5Es was the teaching 
framework applied to all groups. An analysis of the results demonstrated that the learning outcomes of students that used Makey-Makey were better compared with the other two groups.

Implementing the flipped classroom approach in primary English classrooms in China by Chi Cheung Ruby Yang and Yuanyuan Chen (The Education University of Hong Kong) investigated the use of flipped classroom and non-flipped classrooms in teaching English vowel letters in a primary school in China. Specifically, the researchers aimed to find out the perceptions of the participating students and teachers towards the flipped classroom approach and whether it could be an approach for making students more engaged and enhance their learning. Implications for teaching and further research are drawn at the end of this paper.

Mirac Yallihep and Birgul Kutlu (Bogazici University, Turkey) then write on Mobile serious games: Effects on students' understanding of programming concepts and attitudes towards information technology. They aimed to measure the impacts of mobile serious games on fifth grade students and conducted a five weeks study with two groups of students in a private primary school in Turkey. One group played the mobile serious game Lightbot, which teaches basic programming concepts, on iPad for three weeks while the other had lectures according to the curriculum determined by the Ministry of Education. They found a significant increase in the achievements of the students in programming concepts after playing the Lightbot game over the other group, but that treatment with the game did not create any positive impact on the attitudes of the students towards the "Information Technology and Software" course.

The next article: Providing online exams for online learners: Does it really matter for them? by Hale Ilgaz and Gülgün Afacan Adanır (Ankara University, Turkey) note that as online learning has grown in popularity this has led to more widespread use of online exams, which are becoming the preferred method of assessment in both online and traditional learning environments. Their study aimed to investigate the academic achievement of online learners in online exams as compared to traditional exams and to analyse their perceptions towards online exams. Participants of the study were vocational college online learners at a state university in Turkey. The majority of the learners pointed out that online exams are efficient, usable, and reliable while others indicated a level of insufficiency related to exam duration, as well as concerns about potential technical problems that may occur during the implementation of online exams.

Anne L. L. Tang, Vincent Wing Sun Tung and Tiffany O. Cheng (The Hong Kong Polytechnic University) offer a conceptual paper exploring the pedagogical implications of educational robotics (ER) in management education in their article: Dual roles of educational robotics in management education: Pedagogical means and learning outcomes. Premised on Vygotsky's social constructivism, their paper conceptualises ER as a stimulus for serving dual roles, as a pedagogical means and as a learning outcome, by presenting a number of justifications and viable approaches. They suggest that ER presents a number of opportunities for facilitating learner-centred, experiential, and collaborative pedagogical approaches to address different learning needs and knowledge levels.

Using an E-book in the secondary English classroom: Effects on EFL reading and listening describes a study by Yufen Hsieh and Siouwun Huang (National Taiwan University of Science and Technology). In their research an experimental group utilised an e-book in regular English class, while the control group used a print 
version with the same content. An achievement test and focus-group interview followed the six-week e-book intervention and showed that the e-book had a positive impact on listening comprehension, particularly for low-proficiency students. For these students, multimedia input combined with a standard accent seemed more effective for the development of listening skills than access to only the foreignaccented English spoken by the teacher. Pedagogical implications of the results are discussed.

Association of learning styles with different e-learning problems: a systematic review and classification is from Aditya Khamparia (Lovely Professional University, India) and Babita Pandey (BabaSaheb Bhimrao Ambedkar University, India). They point out that didactic learning is limited in providing a flexible or dynamic e-learning environment to students due to increase in complexity of modelling human behaviour in a virtual environment. The purpose of their study was to review learning styles having different classification methods associated with different e-learning problems. The study examined the effectiveness of learning style and different classification methods in various e-learning problems and to support researchers, academicians and practitioners in effectively adopting learning styles and methods corresponding to learning problems.

David John Lemay (McGill University, Canada) and Tenzin Doleck (University of Southern California, USA) then offer: Grade prediction of weekly assignments in MOOCS: mining video-viewing behaviour. They assert that Massive Open Online Courses (MOOCs) hold the promise of democratising the learning process, but that providing effective feedback has proved hard to offer at scale since most methods require a teacher or tutor. Leveraging big data in MOOCs offers a mechanism to develop predictive models that can inform computer-based pedagogical tutors. They found that in a MOOC organised around weekly assignments frequency of video viewing per week is a better predictor than individual viewing features such as plays, pauses, seeking, and rate changes.

E-learning readiness of universities in Nigeria- what are the opinions of the academic staff of Nigeria's premier university? is from Williams Ezinwa Nwagwu (University of South Africa and University of Ibadan, Nigeria). This paper examined the opinions of academic staff of the University of Ibadan Nigeria regarding the preparedness of stakeholders of e-learning in Nigeria for fruitful e-learning experience and action in Nigerian universities. The lecturers considered e-learning as an add-on, as they expressed an inability to integrate e-learning into their current tasks and do not have the time to do so. Their assessment of e-readiness of students indicated that the lecturers were undecided on whether the students actually know what e-learning is, and have sufficient IT and web skills required to drive e-learning.

Augmented reality technology has recently become one of the primary technologies for science education say Bahar Baran (Dokuz Eylul University, Turkey), Esra Yecan (Pamukkale University, Turkey), Burak Kaptan (Dokuz Eylul University, Turkey) and Ozan Paşayiğit (Izmir, Turkey) in their article: Using augmented reality to teach fifth grade students about electrical circuits. They point out that although augmented reality is attractive, a need exists for good content, implementation, and evaluations, as in every technology integration process and their study aimed to develop and evaluate an augmented reality application to teach two groups of fifth grade students about electrical currents. In the first the students were taught an augmented reality 
assisted electrical circuit lesson in a group, while in the second the students studied individually. They found that attitudes of the students studying individually toward the augmented reality applications were significantly higher than the students studying in a group, but that no significant differences existed in the students' attitudes toward science and technology courses.

Automatic detection of students' affective states in classroom environment using hybrid convolutional neural networks is offered by Ashwin T. S. and Ram Mohana Reddy Guddeti (National Institute of Technology Karnataka Surathkal, India). They point out that predicting the students' emotional and behavioural engagements using computer vision techniques is a challenging task and that there are several state-of-theart techniques for analysing this in an e-learning environment (single person's engagement detection in a single image frame), but very few are available for analysing the students' affective states in a classroom environment (multiple people in a single image frame). In their paper they propose a novel hybrid convolutional neural network (CNN) architecture for analysing the students' affective states in a classroom environment. This proposed architecture consists of two models, the first model is designed to analyse the affective states of a single student in a single image frame and the second model uses multiple students in a single image frame.

The cloud computing platform has become prevalent today and is being utilised by many organisations in government, industry, and academia. Cloud adoption for elearning: Survey and future challenges by Minhaj Ahmad Khan (Bahauddin Zakariya University, Pakistan) and Khaled Salah (Khalifa University of Science and Technology, United Arab Emirates) presents a taxonomy of cloud usage for e-learning, and also analyses existing major contributions relevant to cloud usage for e-learning. They also describe a comparative analysis of the frameworks and models found in the literature along with a comparative evaluation of the implementations carried out for e-learning.

The last 'regular' paper in this issue: A computer design method of an effective educational trajectory in blended learning based on students' assessment is offered by E. M. Ivanova and A. V. Vishnekov (National Research University Higher School of Economics, Russia). They note that the problem of students' motivation to learn an ever-increasing amount of knowledge (especially in the field of information and communication technologies) is more relevant than ever, but can be solved on the basis of students' active involvement in the educational process. Their paper surveys modern approaches to motivate students to participate actively in the educational process, with a detailed description of the method used to design the most preferred educational trajectory with the participation of students, teachers and the university administration. This method was tested by students in the Computer Systems and Networks master's program at the National Research University Higher School of Economics (Russia).

Articles in this issue of our truly international journal come from researchers in: Australia, Canada, Ghana, Greece, Hong Kong, India, Iran, Malaysia, Morocco, Netherlands, Nigeria, Oman, Pakistan, Philippines, Portugal, Russia, Saudi Arabia, South Africa, South Korea, Sweden, Taiwan, Turkey, Uganda, UK, United Arab Emirates, USA and Zambia.

In addition to the regular articles in this issue, also included is a list of all the reviewers who completed at least one (and in a lot of cases many) EAIT review in 2019. Completing a review for a journal article is a significant task requiring 
considerable time and effort and each review makes a very important contribution to the journal. Springer, the Associate Editors and I thank you all for your effort and dedication.

Arthur Tatnall.

Editor-in-Chief. 